\title{
THE TOURISM ETHNIC SPACE AND ITS SYMBOLIC INTERFACES
}

\author{
Danielle Marian Araujo dos Santos ${ }^{a}$ \\ Francisco dos Anjos ${ }^{b}$ \\ Joelma Monteiro de Carvalhoc \\ Luciano Torres Tricaricod
}

\begin{abstract}
This article discusses the touristic ethnic space in an indigenous community located in the metropolitan region of Manaus. The study is based on the ethnic perspective, as a historical construction of the identity of a specific group of people, a social group that has a different way of life from the urban world. The research purpose was to analyze the absolute, relative and relational space of a touristic indigenous community, pointing out the territorialities that were built from the touristic activity. The methodology was based on an exploratory study, and the geographic constituency was the Sahu-Apé community, in which it was possible to identify not only the functional dimension, but also its symbolic dimension within the space formed by a set of unique symbols of the ethnic group, compared to other groups. For Haesbaert (2004), these mastery constitute the identity and establish the ways in which relationships are built in indigenous societies based on their ancestors. As main results, it was found that the identity of the Satere people is configured in its most important object in the tourist activity, and the physical and symbolic space is the tourist product that has been built over time.
\end{abstract}

\section{KEYWORDS:}

Ethnic tourism

Touristic territory

Symbology 


\section{INTRODUCTION}

The community's identity is itself a unique mark and was built over centuries of history of the Sateré people. Almeida (2007, p. 49) points out that "Any identity process cannot be sufficiently apprehended without taking into account its social process of territorialization". The construction of this group identity happened from a long process of struggle for land and for its valorization.

Tourism interfered in the new form of territorialization of the Sahu-Apé community, which materialized in changes in the organization of improving, in the implementation of other cultural activities that could be appropriated as tourist attractions, and in the refunctionalization of existing elements. These changes have generated new income alternatives that make it possible for residents to remain in the place. In this sense, Santos (et. al 2019, p. 08), state that, "the reflections on income alternatives, which are obtained through the use of indigenous cultural heritage, must precede an analysis of the vision these peoples have about themselves and about these economic alternatives".

The objective of the research was to analyze the absolute, relative and relational space of a touristic indigenous community, pointing out the territorialities that were built with the touristic activity. In this perspective, the territoriality initially limited to what everyday life needed to be changed over time. The demand for tourism increased the dissemination by the media and increasingly they were led to expand the number of attractions in the place.

How then does this territorialization happen in the dimensions of the community space? This touristic ethnic space is analyzed here from three dimensions: (Harvey, 1973), absolute space, relative space, and relational space and their symbolic interfaces.

The study is important because it analyzes the process of territorialization of an Amazonian indigenous community, and the spatial organization from different dimensions and views of the same space, if it is absolute, as physical and concrete space, relative, from the elements that form it, or relational, based on the relationships that are established between people and objects in this space having as a basis for these objective and subjective constructions the tourist activity. In this way, it is possible to understand the reality of the place and the influence of the tourist activity in the region.

Methodologically, it is a qualitative, descriptive and exploratory approach. Residents over 35 years old and at least 10 years old were selected in Vila do Ariaú; a period in which it was possible to monitor the intensification of tourism in the Sahu-Apé community.

\section{DEVELOPMENT}

\section{Absolute space: A look from the place}

The absolute space of the Sahu-Apé community is characterized by the shape and structure of the place where the village was installed and by the buildings and spaces created by it, within the legally delimited area. This space, in the words of Lefebvre (2000, p. 78). "(...) It consists of nature fragments in places eluded by their intrinsic qualities (cave or summit, fountain or river), but from which consecration ends up emptying them of these natural characteristics and particularities."

The absolute, fixed, palpable and planned space, in the case of the research object, is formed by the hectare where the community was built and the residents interact and collect their resources. Place where they live their daily lives regardless of tourist activity and where they do it. It then constitutes the physical space structured in a specific way.

In the Sahu-Apé community, the space was reorganized based on the demand for tourism. The community already existed in an absolute way as a living space. Tourist territorialization initially happened to maintain survival. The use of natural resources was solely for the collection of food and raw materials for handicrafts for personal use. When the daily lives of residents began to draw the attention of agencies and guides to tourist activity, new forms of territorialization were established to meet this demand.

Culture was not created to entertain the tourist. The community already existed before anything else as the "home" of the indigenous people. With the rise of tourist activity, residents began to expand their territory by using and giving it different forms, making it more attractive to tourists, but not constituting a staging. It is these two spatial realities that form the basis of the dialectic of this analysis and lead to an understanding of the material space or perceived experience, expressed in the statements that demonstrate that spaces beyond the legal territory of the community are explored.

The space design element is represented by maps of limits and displacements. In the content analysis of the interviews, it was possible to identify the residents' feelings towards this place where they live. The community emerged from the need to build houses for the indigenous people who were already involved in the performances of rituals in jungle hotels close to the community.

The origins of the people are marked in its territory, which is a historical space. About this Lefebvrand (2000, p. 79) "the absolute, religious and political space, produced by communities of blood, terror, lan- 
guage, proceeds from the relativized, historical space". The residents of Sahu-Apé live in a physical space that is also a social space that was created under their own imagination with the characteristics of their ethnicity. The territorialization of this space happens as this social group finds ways to use and modify this same space, and when this use is related to tourism, the touristic territory gains its own characteristic. The spaces, according to the interviews, have meanings such as: "The trail that starts at the entrance of the community leads straight to the kitchen, where visitors get to know more deeply about the way of life of the indigenous people; how they eat, how they communicate as a family and as an organization; where they receive organizations that will provide service to residents, that is, where the community lives together for longer. And there is also a symbolism in this space, as it is community food, it is also the place where "relatives" can expose their problems, their doubts, where the community makes decisions when there is no outsider. It is the administrative heart and where meals are blessed." (SAHU, 2020)

Among the most important and sacred spaces is the Kunã, or pharmacy. There is the abode of the forest spirits, the spirits that take care of the indigenous people of the community, where the shaman prepares his medicines and potions, which from the perspective of tourism, it is the most mysterious place, where you can feel the presence of these spirits. For Gandara and Mello $(2019$, p. 11) "the imaginary element of the sacred in tourism symbolizes a human tendency to adore the mysterious and fascinating understood as a quality of the different".

During tourist visits, the Pajé showed a very pleasant perfume that has mysterious properties, which attract the opposite sex. "a tourist from Rio de Janeiro, bought two small bottles of about $20 \mathrm{ml}$ each. Two months later, she called and asked me to send her 1 liter of the aforementioned perfume, as, according to the visitor from Rio de Janeiro, it had a positive effect".

When observing the Sahu-Apé community, in the metropolitan region of Manaus, we find that tourists have sought out indigenous spaces to hear the narratives and experiences of these people. An example of this is the visit to the indigenous pharmacy, called kunã, where the shaman explains the mystical and curative properties of his medicines, interacting with tourists and, sometimes, diagnosing the "evil eye" ${ }^{\prime 1}$, healing the mind and body. Talking to Birth (2013), the preparation of medicines is a ritual, as it involves specific knowledge and actions. Likewise, the spiritual cure in the indigenous pharmacy is the place to prepare medicines with medicinal plants from the Amazon, rue, vinegarlic, mastruz, among others, also using other products such as bee honey.

In the ethnographic field, we witnessed in the SahuApé community the removal of honey from the houses where the bees produce it; they feed on the local native plants, without risk of pesticides, which allows the production of pure and high-quality honey. On this visit, we witnessed groups of tourists who purchased $20 \mathrm{ml}$ of honey, in the amount of $R \$ 25.00$ (twenty-five reais). This fact demonstrates that tourists sought the exotic, what was authentic and different from their reality, hence the purchase of a product that. In addition to being produced by indigenous people, it was also free of preservatives.

The strength of herbs and also the strength of mysticism can influence the healing of sick who seek some remedy, but the herbs used have been part of the indigenous people's daily life for centuries, reported the shaman Sahu (oral communication in September 2020). Tourism practices by themselves do not build the ethnic territory, it is preexisting, even though it is influenced by tourism in its configuration.

For Coriolanus (1998, p. 22) "tourism is, above all, a geographical experience". It's in the geographical space that cultural elements are printed, and it is how a social group is territorialized, that one can understand the cultural dynamics of this group and its history. Tourism is the geographical experience. It is looking at the fauna and flora, their colors, and feeling the smells. The geographical experience is based on the senses that the tourist stimulates during the visit.

Currently, the community has new homes with the growth of children and young people who got married and are already seeking to form their families. The emphasis of the visits is on the central area of the community and on the elements of nature that surround it, such as the forest and the river. The social center or shed is the place for presentations to tourists, where the center of the community is expressed.

The relationship between man and nature, with the elements of the environment and with the inhabitants of a given place, characterizes the geographical and tourist experience. In the ethnic segment, tourists seek authenticity that is expressed in the ways of life and identity of ethnic groups. (Brazil, 2004).

In this configuration of space, there is initially the distribution of community members. For Lefebvre (2006, p. 246) "the absolute space, that of religion, introduces highly relevant oppositions between word and writing, between the prescribed and the forbidden, the accessible and the subtracted, the full and the empty".

In the culture of the Sateré people, historical narratives are relived in festive moments, such as the "Ritual of Tucandeira, which is characterized as the

${ }^{1}$ In the Amazonian conception, it means a person who gets sick from the evil eye of the other 
boy's rite of passage to adulthood" (Carvalho, 2017, p. 55). In this sense, the final configuration of the use of ritual space is beyond objective interests but relates to how this ritual should happen and how social categories should be organized in this space. Women also participate in the ritual when they want to, but without obligation like men. They are on the right side and when there is interest and with Tuxaua's consent, they are called on (Oak,2015). Children stand beside women because they are considered fragile, but they need to attend the ritual to learn how it happens and to gain courage to participate when they are of the appropriate age.

A group of tourists "gringos" who spoke in Spanish criticized the ritual, because it was "cruel", it caused pain in the boys and girls who put their hand in the glove. The tour agency guide who had scheduled the visit explained that it would not be cruelty, but a way to prepare them for the future warrior for the dangers of the forest, as the indigenous need to have resistance. This is a way to experience their customs, even if for the "white" view it seems inadequate. It is necessary to draw attention to the skills that this ritual represents in the life of the indigenous.

This condition requires the development of knowledge and skills that are represented in rituals, especially in the tucandeira ritual, where pain and courage are mixed to show the strength of the warrior (Carvalho, 2015).

This is the identity of the indigenous, it is their product that attracts tourists, because, as reported by Lima, Assis and Moura (2013), tourism based on ethnic elements is attractive to the identity and culture of the group, as is the case with Afro-descendants of the quilombolas, gypsies, Eskimos, the indigenous people, etc., (Lima, Assisi and Moura, 2013, p.14)

Ethnic tourism is effective in the interest of the visitor in a way of life that is different, which interests and even shocks in some situations, which intrigues, intimidates, enchants and marks its history.

In the Amazonian conception, it means a person who gets sick from the evil eye of the other.

Person who was not born in Brazil; foreigner: like a good gringo, he loves Carnival. (Aurélio Online, 2021)

\section{Relative Space}

The relative space is built from the circulation processes of the residents in the village of Ariaú, in the city of Iranduba and in the capital Manaus, as well as the social relations between the indigenous people, residents of the village of Ariaú and institutions that leave their bases to serve the community.

The relativity of space is established by the ways in which the indigenous relate to objects and buildings in the community, these functions in space and how they change. In this case, a study of how the structures and resources within the space fit into the tourist activity. For Lefebvre (2000, p. 19).

Space, relative, instrument of knowledge, classification of phenomena, is no less separated (with time) from the empirical; according to Kant, it is linked, a priori, to consciousness (the "subject"), to its internal and ideal structure, therefore, transcendental, therefore, inapprehensible.

These elements were represented by thematic maps that express the changes in the form and function of the community and in the content analysis of the interviews; Such elements generate tensions between the indigenous people and the community's residents since its installation.

The relative space is also the perceived space of the community, where it goes and where relationships are built. For Lefebvre $(2000$, p. 65) perceived space, everyday reality (the use of time) and urban reality (paths and networks linking places of work, private life, leisure). In the studied reality, how are the contact and communication networks established between community residents and residents of the Vila and the capital.

However, ties with the city are still strong and this is the seat of Indigenous Health meetings, as it has other municipalities around it. The village became more visited when the tourist activity was implemented. However, not the village as a whole, but the community where the visitors met the indigenous people. Despite the income alternative still lives in difficulties in several dimensions, families are still outside government policies and receive little assistance from public institutions in the areas of health, education and security. This situation extends to its neighbors. (Almeida, 2007). The river that runs through the community is used by residents for fishing. Fish has only use value for the residents, it is only for the subsistence of the indigenous people and has no exchange value. The forest is also a place for collecting seeds, fruits, hunting and has been done for several years. Currently, it is even more exploited by men in the community in search of food and by women who seek raw material (seeds, branches, dead animal teeth, leaves, feathers) for handicrafts. Almeida (2007) points out that urban pressure creates cultural borders and new specific territorialities built by each ethnic group. This territory is then the expression of a social movement that configures itself in new territorial organizations.

In the figure below, it is possible to understand which location of the Sahu-Apé community is related to the forest, the river and the road. These elements directly affect the attraction and viability of tourist activity.

\footnotetext{
2 Person who was not born in Brazil; foreigner: like a good gringo, he loves Carnival. (Aurélio Online, 2021)
} 
Figure 1: Location of the community and its surroundings

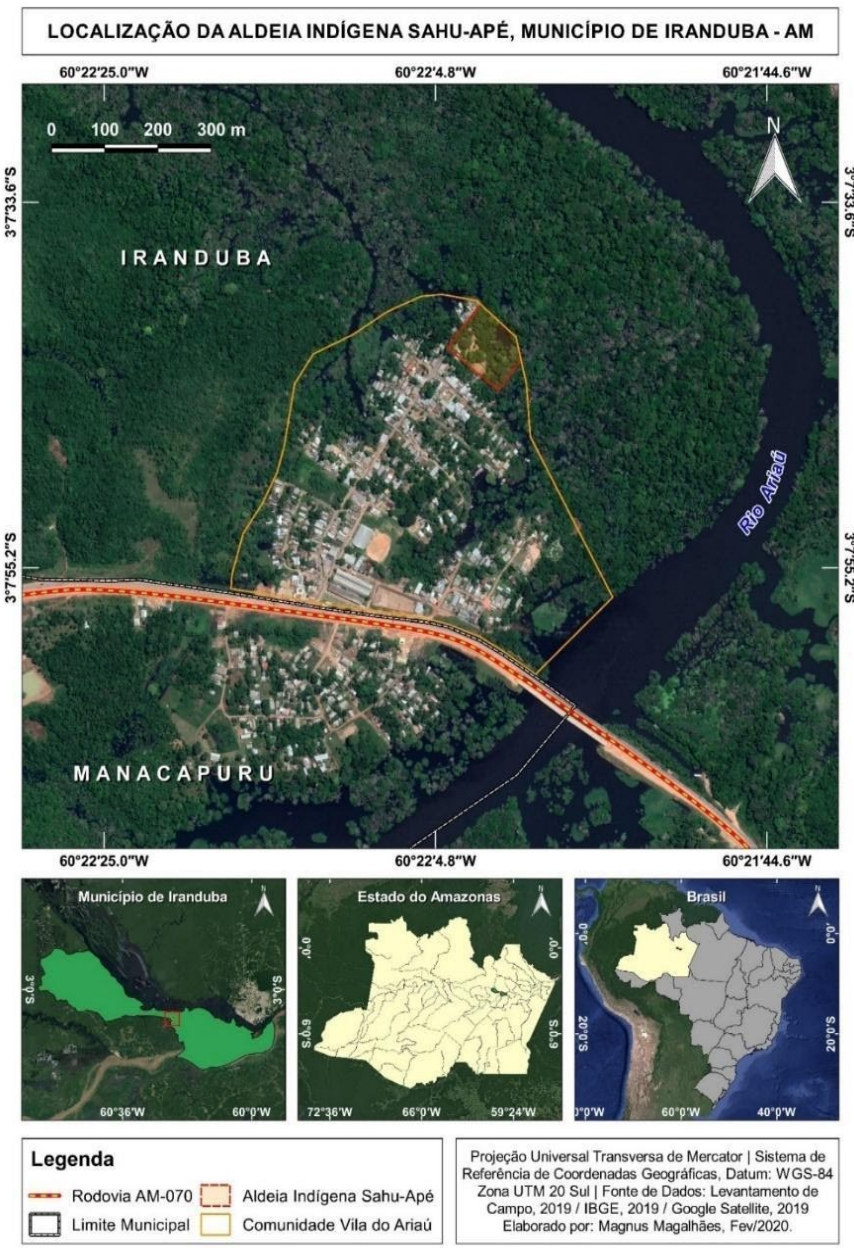

Source: Elaborated by Magalhães (2020)

The community is located inside Vila do Ariaú. We visited in January 2020, with 22 residents of Vila do Ariaú (11 men and 11 women), to understand the vision of these residents regarding the process of implementation and territorialization of the indigenous community, as well as in relation to the processes involving the tourist activities that happen in function of the community.

The profile of respondents and residents was of parity between men (50\%) and women (50\%), most of them $50 \%$, over 31 years old, prevailing as the most common professions, domestic (56\%), farmers (27\%) and traders (23\%) (figure 2). Most residents have at least completed elementary school (36\%), therefore already literate. Another important fact regarding the formation of the interviewees' profile is the length of residence in the village, as $(68 \%)$ has been living in the place for more than 20 years, which allows them to express more assertive opinion on the topic addressed (Figure 3).
Figure 2 and 3: Data from Vila do Ariaú (2020)

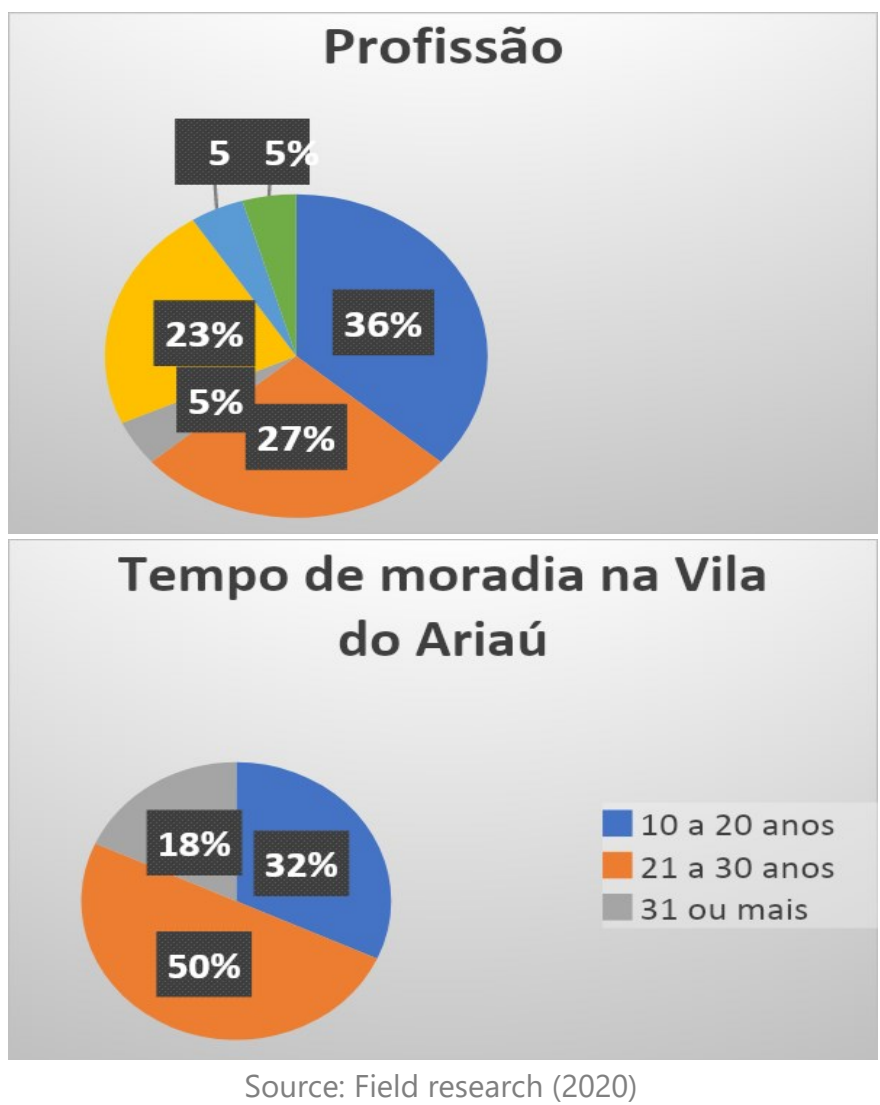

Four questions were asked to the inhabitants of the Vila, where initially the type of contact with the inhabitants of the indigenous community was verified and what they thought about them. Then, directly addressing the issue of tourism, what the residents think about these visitors, how they perceive these visits in the indigenous community and what kind of investment could be made to intensify this activity in the village as a whole.

\section{Relationship with the Indigenous Community}

All respondents reported having contact with residents of the indigenous community. Sport was cited by most interviewees as a means of contact with indigenous peoples. It was found that exactly half of the interviewees had a good relationship with the indigenous people due to their occasional coexistence at high school parties, sports activities or political meetings.

The other half of the interviewees is divided between negative and indifferent views. Among the positive comments, there is a statement by a military resident who followed a situation in 2011 in which the village administration filed an action against the villagers and had the intention of evicting them from the place, alleging constant conflicts related to the Earth.

In the 2020 interview with Pajé Sahu, the conflicts were 
caused solely by the village residents' lack of acceptance of the economic development of the community and that the indigenous people did not cause conflicts, but always asked public management that the benefits could be extended to the surroundings of their land and benefit everyone from Ariaú.

There is currently a report by residents that there are no more problems in view of the integration of the indigenous people with the village, participation in activities and even the decrease in visitors due to the economic situation and the pandemic. The fight for land has already happened, but the main fight was for respect and for the right to live together in a village of "white people". The intervention of the public power was necessary so that the Satere could continue on the land that had been donated to them for years.

About the fight for territory, Medeiros (2008, p. 225) states that "it is within this struggle for the conquest of social space and territory, through the organization of social movements, of their subjects (...) that it is convenient to consider the dimension of power that is present so much in space local and global. Sposito and Sachet $(2008$, p. 326) point out that "Tourist territorialization is one of the faces of the territorialization of capital, driven by the post-Fordist phase of capitalism and marked by flexible accumulation, in which nature and culture are increasingly transformed into merchandise".

In view of the indigenous narratives, it is noticeable that the relationship with non-indigenous people is based on the incomprehension of cultural expressions, different from the "whites", and on the prejudiced construction of the community's image's residents.

\section{Relational Space}

The relational space, based on the categories presented by Harvey (1973) was presented in this study through the relationships that are established between the elements of the community space and its residents and represented through maps that register how its dynamics happened over time.

It also refers to the representations and meanings of the elements of the space, whether in the simple daily life of residents or during tourist activities. In this perspective, the relational space also expresses the symbolic space, based on the relationships that are built between man and his elements. Finally, there is a space that is contained in the things themselves. "This is the relational space, in the face of which an object exists only insofar as it contains (and represents in itself) relations with other objects". (Harvey, 1973, p. 13).

To characterize the relational space within the village and how it is expressed in its territorialization, it is necessary to understand the meanings that each element has for the Satere ethnic group. These indigenous men and women build their place of dwelling, considering the various symbols and expressions of their past, history, inherited from ancestry. Eliade (1992, p. 26) states that "Setting up in a territory, building a home requires a vital decision, both for the community and for the individual. It is about taking on the creation of the "world" that one chose to inhabit. It is therefore necessary to imitate the work of the gods, cosmogony".

The Sahu-Apé community then reorganizes its space, establishing a territoriality that expresses not only its symbols and mythology, but also the way to serve the tourist activity. This adequacy does not destroy the magical paths but highlights them as an element of attraction. Every day, new spaces inside and outside its legal limits are added to the tourist activity. Kunã, in the words of Mr. João (Wató), is built on a stone that symbolizes grandpa's house, who protects the village (Figure 4).

Figure 4: path to Kunã and Pedra do vovozinho.
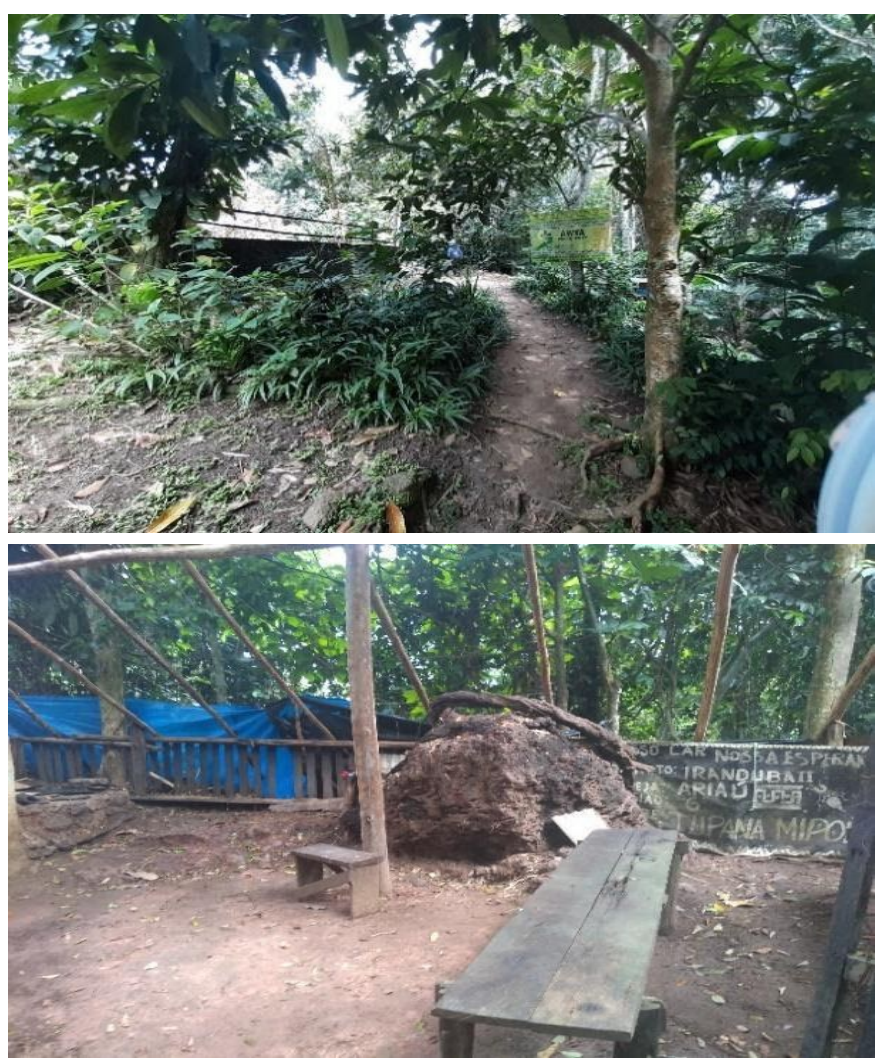

Source: SAINTS. DM (2019)

The image of the stone mentioned by Mr. John who represents this spirit. In this image, the cover is missing because the straws were being changed due to natural wear. "This place is spiritually sacred for us, where we smoke and take medicines, we believe that it is grandpa's house, which protects the village. Access there is for shamans and healers, it is not for everyone, children cannot go there" (João Wató, 2020).

When visitors are taken to the site, they are required to show a lot of respect, they need to be silent, and atten- 
tion is required to the shaman's speech and his explanation of how the medicines are made. In the symbolic understanding, it is the space that houses Sateré's spirituality and is located in an area far from the houses and the movement, demonstrating the pharmacy relativity in reference to other spaces.

Another evidence of the symbolic space is the kitchen, which as discussed above, is the place for everyone to meet and eat. In relation to the other buildings in the village, it is right in the center, symbolizing the meeting, the gathering of residents. In the words of João Wató (2020), "It has access to the entire community...a community, collective place, where agents meet".

At the reception of tourists, it is the first place they pass through and are welcomed, where knowledge about the history of the community begins. In this place, banners of research already carried out in the place, old photos and objects used by the residents are exposed. The kitchen tradition was maintained, being transformed into a tourist attraction (figure 5).

Figure 5: Shed where the community kitchen is located.
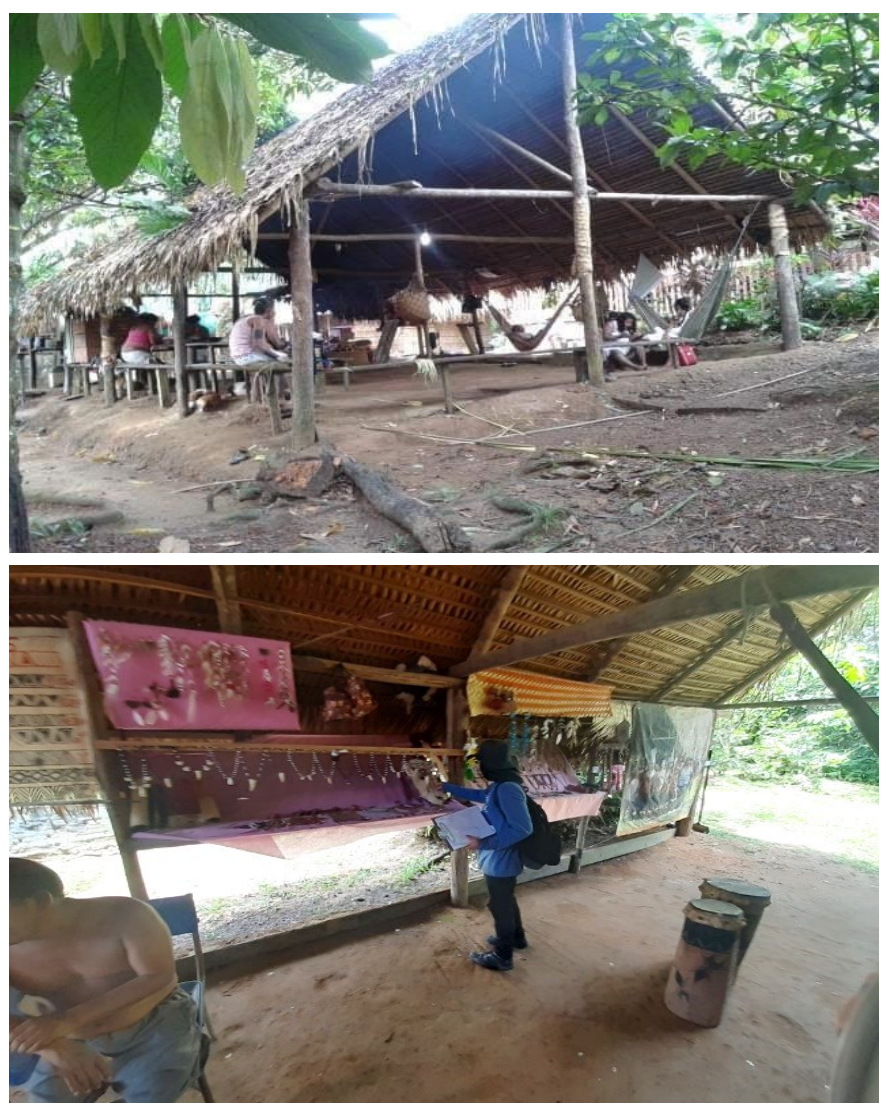

Source: FREITAS ZSN (2019) Source: SANTOS DM (2020)

The kitchen is for the community, a place of joy and meeting. It symbolizes reception and fellowship. At the site you can also see the exhibition of Sateré handicrafts.

The handicrafts visibly displayed are made by the families and each one has its space divided so that they can be displayed and purchased by visitors. Handicrafts are an important source of income and through them, the indigenous people express ethnic elements. Amirou (2007, p. 34) states that "the journey begins by being imagined, then it is lived and finally, on the way back, it is said, commented, illustrated by photos, films and souvenir objects (...)". Sateré handicraft reinforces the indigenous identity and the relationship they build with nature.

The wealth of details expressed today in the visits is nothing more than a rescue of symbology's forgotten over time and pressured by the urbanization process. Young people, in the words of Mrs. Baku, forget that they are indigenous and no longer care about culture and the elements of nature.

The Sahu-apé community also holds its events that usually happen on the Indian's day and in November, the rainy season and when the tucandeira ants need to go to the surface of the soaked soil and appear in abundance, and as the indigenous say, they come "angry". For this event realization, disclosure is made both among other villages and among agencies. It's a special time for young people who spend months preparing for the event. They will undergo a very important test of strength and courage in front of their relatives.

For the tuxaua, "rituals strengthen our culture". For the tuxaua of the Sahu-Apé community, Ms. Midian da Silva, "every boy (curumim) has to complete the stages of the ritual, I have no feeling for the pain, this is part of our culture, it is the ant that heals and that will become a warrior". She demonstrated the recognition of the divine and the sacred within the indigenous daily life.

For Levi-Strauss (2014, p. 41), in any mythology, "there are deities or supernatural characters, who play the intermediary role between powers from above and humanity from below". These brands in a contemporary context are exposed in graphics, with commercial value. In the linen closets designed by the indigenous Sateré-Mawé, the graphics gain expressions of animal skins, such as snakes and armadillos, which give new meaning to the large maloca.

About the symbolism in the ritual presented in the community, it is verified that the use of the elements of nature happens in a different way each time. More specifically, as seen in the words of Sotratti (2020, p. 01) "The relational notion of space, in turn, implies the idea of internal relations, according to which an event cannot be understood from a single point, but will depend on everything that happens around it".

Symbolisms are expressed in each of the following moments in the ritual. There is the preparation of the glove for the Tucandeira ritual and its realization in the cultural center area of the community, figure 6 . In the symbolism of the ritual, all the elements come from that piece of land where the residents live; they are fruits of the village, both the living elements as well as 
the resources used. Space is sacred, is lived and is relative to each event that happens in it.

It is a space and time of extreme importance in the reality of indigenous peoples. The ritual can only be performed there, as the warrior spirits dwell there $(O a k, 2019)$. This is the characteristic of relational space. It is not the space itself, but its relationship with other elements, objective or subjective. They are "amazed" when putting on the glove. About this feeling, Amirou $(2007$, p. 46) indicated that "The more adventurous the journey, the greater the work of imagination before departure".

The territory understood as the space where human relations impose their power, and territoriality understood as the process of appropriation of this space, the way in which man gives meanings and values to the elements of this space, is then the construction of the notion of relational space. It is the moment of the ritual that links the "gringos" (foreign visitors) and Brazilian and indigenous tourists.

Figure 6: Preparation of the Tucandeira ritual in the community.
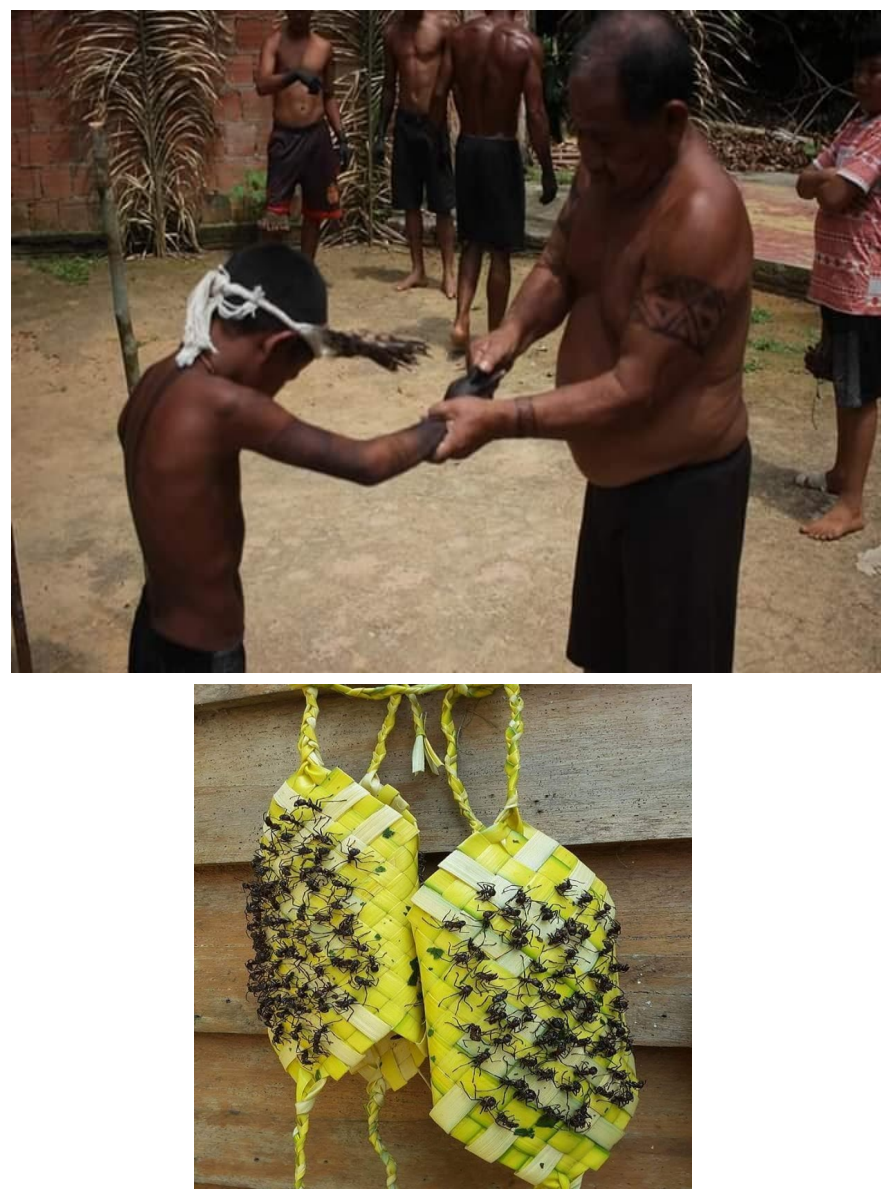

Source: FREITAS ZSN (2019)

The images shown in Figure 6 show the preparation of the glove with the ants, then the explanation of the ritual for the visitors, the spiritual preparation of the warrior made by the oldest indigenous person, and then the glove about to be used.
Visitors who take risks can then feel warriors, strong, virile like the native at the moment of their pain endurance test. But given the whole socio-historical relationship of indigenous culture and tourism in the State of Amazonas, there was an intriguing fact: there is no mention in the official calendar of the Tourism Ministry events in 2019 of indigenous ethnic events.

This socio-historical indigenous construction in the region is represented of practically all festivals in the cities in Amazonas State and other states in Northern Brazil, intertwined with the people's lives and present in Brazilian culture, even in a hybrid way with other cultures, in institutional and formal perspective of tourism, still demonstrates its fragility.

In ethnic tourism, the presence of marketing goes through the tourists themselves who by experiencing experiences with indigenous people, disseminate the services provided by them. In the Sahu-Apé community, the tuxaua Midian stated that "many tourists schedule visits to get to know the daily life of the residents, participate in the ritual, live with the shaman using homemade remedies", these, in turn, are prepared with herbs extracted from nature.

At herbal infusions as a natural drink, also known as cachaça, is a stimulant, and along with cigarettes, maraca and prayers, they are also part of Tupi shamanism, a healing process of the shaman (River, 2000). The cosmogonic mystique has awakened the collective imagination of those who visit the communities, promoting the empowerment of those who inhabit it and increasing the possibilities for maintenance and conservation of peoples and the environment. Ecological issues have been the flag of struggle for indigenous people, in order to guarantee the survival of the planet.

Indigenous ethnic tourism in Amazonas has not yet been consolidated as a strong segment supported by public agencies. It has not yet been systematized as the State's tourist identity, nor has its events been disclosed in the official events calendar.

This situation is concretely expressed when the precariousness of some villages that receive tourists is verified, in the lack of preparation and technical monitoring in the construction of itineraries in the villages, and also in the lack of a sense of value that exists, for example, in relation to the handicrafts sold by the indigenous people.

In the meantime, the Amazon Forest, since its colonization, is considered exotic and feared for presenting a diversified culture, permeated by myths and a certain mystery in its lands, moreover to providing countless riches of fauna and flora. Regarding the exotic term, we emphasize that in the European language it means one who is not a native of Europe or Western people (Oliveira; Zeferin; Pinheiro, 2019), and it was from this colonizer's thinking that the exotic Amazon was spreaded. 


\section{Final CONSIDERATIONS}

Tourism activity in the Sahu-Apé community, as well as in other indigenous communities, is built on the expression of the culture of these people. It is the symbolism expressed in the multiple relationships that are established with the elements and phenomena of nature, which form the cultural and immaterial heritage of indigenous people. This heritage and its territory are the sold products to tourists arriving in the village.

The absolute space to which the study refers demonstrates the physical configuration of the elements that were and are built daily in the small fragment of this place. It is the space of exchange, of action specifically established by symbolism and by capital, in this case, tourist activity. It is nature that feeds the men and women who live there.

In recovering the understanding of relative space, it is an instrument of knowledge, classification of phenomena and is directly related to human experience, with its consciousness (Lefebvre, 2006). These experiences, good or not, build the history of the people. The struggles for land also demonstrate the mistaken and discriminatory view of the "whites" in relation to the indigenous people, but it can be concluded that this view is generated mainly by the feeling of neglect by the public power, by the inhabitants of the surrounding villages.

Given this, it is important to look at the touristic indigenous territory and the relationships established in it, considering the context in which it is inserted, the internal and external power relations and the political forces that interfere in the social organization of these communities.

The relational space, "is essentially qualitative, fluid, dynamic." (Lefebvre, 2006, 70), and is understood from the understanding of indigenous intentions and how they build a relationship with each other. These "others" are neighbors, relatives, organizations and the State. It is the action space for tourism to fully establish itself and fulfill its objective, which is to make the community economically viable.

In the current context, the need to sustain the ancestral heritage gains new forms of hybridized knowledge, without losing the essence of the mythological sense. For Canclini (2008, p. 70), "cultural hybridization is a sociocultural process in which structures or practices (..) combine to generate new structures, objects and practices". Despite hybridization from the outside world, indigenous people still seek to curb cultural conservation efforts. In this discussion, Burke (2003, p. 14) considers that "cultural globalization involves hybridization". These changes happen gradually within the communities, without determination, adapting to the new to attend to their own needs.

In this sense, indigenous tourism from the perspective of the Amazon still represents a great potential, as it has only been developed on a small scale and restricted to the surroundings of Manaus city.

Finally, the comprehension of the space's subjective dimension and how relationships are established from different configurations brings the discussion of tourism as a vector of change that would not be possible without it. The activity then refunctionalizes not only physical spaces, but also creates new links and relationships.

\section{References}

Amirou, R. (2007). Tourism and post-modernism: the metamorphoses of authenticity. Espaces, Tourisme \& Loisirs, (245), 46-53.

Brazil. (2004) Ministry of Tourism. Cultural Tourism: basic guidelines. 3. ed., Brasília: Ministry of Tourism.

Burke, P. (2003). Hibridismo Cultural [Cultural Hybridity].

Canclini, N. G. (2017). Hybrid cultures, oblique powers. Media and Cultural Studies, 73, 422.

Canclini, NG. (2008). Hybrid Cultures. São Paulo: EDUSP.

Carvalho, Joelma Monteiro de. (2015). Tucandeira ritual: memory and cultural tradition of the Sateré-Mawé people. PPGLL UEA. Manaus.

Carvalho, Joelma Monteiro. (2018). Memory and tradition: sacred symbols and religiosity. Vol. 2 Memory and Identities, p. 49. https://cienciadasreligioes.ulusofona.pt/wp-content/ uploads/sites/86/2021/07/VOL-2.pdf\#page=49.

Carvalho, JM de. (2019). Ritual of passage: from indigenous lands to urban areas of the Sateré-Mawé. Manaus: UEA. http:// repositorioinstitucional.uea.edu.br/Acessado in February de 2020.

Coriolano, Luzia Neide MT (1998). From local to global: coastal tourism in Ceará. Campinas, SP: Papirus.

dos Santos, D. M. A., de Carvalho, J. M., \& Tricárico, L. T. (2020). Patrimônio imaterial e o turismo étnico em comunidade indígena, em Iranduba, Amazonas. Turismo e Sociedade, 12(3). https://revistas.ufpr.br/turismo/article/ view/69779. Acessado em setembro de 2020.

Eliade, Mircea. (1992). The sacred and the profane. [Rogério Fernandes translation]. São Paulo: Martins Fontes.

Gandara José Manoel Gonçalves. Mello Cynthia Menezes. (2019). The exotic and the perfect trip in the photographic figurativization of the tourist destination Curitiba-Brazil. Federal University of Paraná (Brazil) Vol. 17 No 1. Pgs. 81-96. Enero-April. https://doi.org/10.25145/j.pasos.2019.17.006.

Haesbaert, R. (1997). Deterritorialization and Identity: the "gaúcha" network in the Northeast. Niterói: EdUFF. 
Harvey, D. (1973). Social Justice and the City. London: Edward Arnold and Baltimore: John Hopkins University Press.

Lefebvre, H. (1991). Formal Logic, Dialectical Logic. Rio de Janeiro: Brazilian Civilization.

Lefebvre, H. (2000). The production of space. Trans. Doralice Barros Pereira and Sérgio Martins (from the original: La production de l'espace. 4th ed. Paris: Éditions Anthropos. First version: beginning.

Lévis-Strauss, Claude. (2014). Myth and Meaning. Lisbon: Editions 70.

Lima, IB; Ismar Borges de Lima; Assis, JNC; Moura, Knr; Lima, Ismar Borges de. (2013). A Contextualized Reflection on the Potential of Ecotourism for a Model of Ethnodevelopment and Social Inclusion in the Indigenous Reserves of Uiramutã and Pacaraima, Roraima. In: 1st Colloquium Tourism in Indigenous Lands: Tourism, identity territories and interethnic conflicts under debate. Goiania.

Medeiros, R. Territory space of identities. In: Saquet, Marcos Aurélio and Sposito, Eliseu Saverio (organizers). (2008). Territories and territorialities: theories, processes and conflicts / T327. 1st ed. São Paulo: Popular Expression: UNESP. Graduate Program in Geography.

Birth. Baku. (2013). A Tuxaua in the Amazon. Manaus: EDUA.

Oliveira, Liliane Costa de; Zeferino, Viviane de Oliveira Lima; Pine, Israel. (orgs.). (2019). Amazon: prospecting for multiple lenses. Alexa Cultural: São Paulo / Edua: Manaus.

Ribeiro, Berta GO (2000). Indian in Brazilian culture. 3rd ed. II series. Rio de Janeiro.

Sahu (Ismael da Silva Freitas). (2020). The situation in the SahuApé village. Interview with Danielle Santos.

Saquet, Marcos Aurelio and Sposito, Eliseu Saverio (organizers). (2008). Territories and territorialities: theories, processes and conflicts / T327 .1. ed. São Paulo: Popular Expression: UNESP. Graduate Program in Geography.

Silva, Adnilson de Almeida; Siqueira Rosângela Bujokas de; Almeida Laura Dominic GS. (2000). Reflections on the rights of indigenous peoples and traditional populations in the Amazon. DOI: 10.17551/2358-1778/geoamazonia. v2n4p56-78.

Sotratti, Marcelo Antônio. Space. (2020). Dictionary. Available in:http://portal.iphan.gov.br/ dicionarioPatrimonioCultural/ Details/62/espaco. Accessed on March 20, 2020. 